\title{
Cognitive Engagement and Online Political Participation on Social Media among Youths in Malaysia: The Moderating role of Political Knowledge
}

\author{
Aishat Adebisi Abdulrauf ${ }^{1, *}$, Norsiah binti Abdul Hamid ${ }^{2}$ and Mohd Sobhi bin Ishak ${ }^{2}$ \\ ${ }^{1}$ School of Multimedia Technology and Communication, Universiti Utara Malaysia; University of Ilorin, Nigeria. \\ ${ }^{2}$ School of Multimedia Technology and Communication, Universiti Utara Malaysia, Malaysia.
}

\begin{abstract}
The role of political knowledge in engendering political participation among youths in a society cannot be overstated. Yet, there is scarcity of research in this area. Thus, this study assessed the moderating role of political knowledge in the relationship between Access to Political Information on Facebook and Twitter (APIFT), Political Interest (PI) and Policy Satisfaction (PS) with Online Political Participation on Facebook and Twitter (OPPFT). A cross-sectional survey was conducted on 238 undergraduate students of Universiti Utara Malaysia. Questionnaire was used to collect data which was analysed using Partial Least Squares-MultiGroup Analysis (PLS-MGA). Results revealed that political knowledge moderated the relationship between access to political information on Facebook and Twitter and political interest with youth online political participation on Facebook and Twitter. However, it did not moderate the relationship between policy satisfaction with youth online political participation on Facebook and Twitter. Generally, these findings suggests that political knowledge plays a significant role in youth online political participation in Malaysia. Consequently, this study has added empirical evidence to predictors of political participation while at the same time contributing to the body of knowledge on online political participation.
\end{abstract}

\section{Introduction}

The use of social media for political participation have grown of recent [1,2]. Thus, they have provided new avenues for political organization such that citizens can participate in politics [3]. As such political use of social media is one of the fastest growing examples of online political participation [4]. In response to this growth is a steady rise in researches in this area [5] with particular reference to the youths.

Consequently, studies have shown that social media have provided youths with new ways of political participation and democratic citizenship [6]. Specifically, studies conducted in the US [7] and Sweden [8] have shown that social media has significantly influenced political participation among youths. However, some scholars have noted that there is decrease or non-participation of youths in politics whether online or offline [9]. Accordingly, researches in this area have presented mixed results. Yet theoretical attention in previous studies have been inadequate [10]. For instance, social capital [11], civic voluntarism model [12], and uses and gratification theory [13], have been used in previous studies. However, limited studies have examined whether youths may participate more in politics through learning about politics on social media. To address this gap, the present study aims to investigate youth online political participation from a cognitive engagement perspective as recommended by [14]. Thus, the Cognitive Engagement Theory (CET) [15] will be extended to social media with an aim to assess the role of political knowledge in moderating the relationship between access to political information on Facebook and Twitter, political interest, policy satisfaction and online political participation on Facebook and Twitter.

To assess this plausibility, we analyzed data from a cross sectional survey of undergraduate students of Universiti Utara Malaysia between March and May of 2015. We study undergraduates because they constitute a key segment of youths in any society [16]. Also, they are early adopters and heavy users of technology [2] like new

* Corresponding author: nor1911@uum.edu.my 
media [17] especially social media, like Facebook and Twitter [18]. Moreover, [19] stated that students of tertiary institutions use social media over nine times more than other demographics in the population. Additionally, [20] establishes that CET emphasizes that those with better education, especially higher education are more likely to be able to understand political information and make informed choices on political participation. Therefore, undergraduates have the skills to better access political information on Facebook and Twitter, which in turn increases their knowledge and interest in politics which could subsequently lead to political participation.

Consequently, greater understanding of the effect on online political participation by youths may have important democratic implications, as concerns over non-participation have long being focused on this demographic [21, 2]. The reason for this concern is because non-participation of youths in politics overtime impedes their representation in the democratic process, which may in the long-run undermine the efficacy of the Malaysian democratic system.

Thus, the present study examines the relationship between features of cognitive engagement and online political participation on social media. Therefore, the overall goal of this research is to advance understanding on how political knowledge enabled by social media contributes to the democratic process through youth online political participation in Malaysia.

\section{The cognitive engagement theory}

The cognitive engagement theory proposes that an individual's political participation is as a result of his education, access to information, political interest, political knowledge and policy satisfaction [15, 22]. Thus, the theory is based on the assumption that the more educated citizens a society have, the better informed they will be and in the long run the more they will participate in politics to show their satisfaction with government policies. Also the lesser the cost of access to information, the more citizens consume information from the media and the higher the level of political knowledge and interest among citizens which further leads to increase in political participation [12]. Originally, CET was proposed in the context of traditional media and traditional political participation. However, the emergence of new media like social media has reduced cost of accessing political information thereby bringing the theory to relevance in the digital age. Thus, in examining CET from social media perspective, it is evident that social media use promotes political participation $[23,24]$. It is noteworthy, that of all the social media sites available, the most popularly used for online political participation is Facebook and Twitter [8].

\section{Knowledge and online political participation}

Political knowledge is information about politics acquired through media particularly social media. As such, [25] noted that one of the most consistent findings in communication literature is that media use is positively linked to higher political knowledge. Thus, media plays an important role in how citizens acquire political knowledge which eventually leads to participation [26].

Consequently, citizens' political knowledge and participation in politics are very important to the democratic process $[12,23]$ such that a decline in political knowledge is partly to blame for a decline in participation [27]. Hence, social media increases citizen political knowledge [28, 29]. Equally, [23] believes youths who are apathetic to politics would be more willing to access political content through social media. Thus, the more knowledgeable youths are, the more likely they will be interested in politics. This is because it will enables them to acquire greater political knowledge and interest, as a result increase their participation [7, 11]. Hence, informational use of social media for political participation such as reading political news have a significant effect on political knowledge and participation [30]. As a result, citizens with more access to political information in form of news on new media are more likely to participate in politics because it increases their combined knowledge since they use the internet as a means of educating themselves about politics [31].

From the discussion above, it is evident that political knowledge is intricately linked to access to information, political interest and policy satisfaction. Hence, the following hypotheses are formulated:

$\mathbf{H}_{1} \quad$ There is significant difference between Malaysian youths who do not have political knowledge and those who have political knowledge in terms of the relationship between access to political information on Facebook and Twitter and online political participation on Facebook and Twitter.

$\mathbf{H}_{2}$ There is significant difference between Malaysian youths who do not have political knowledge and those who have political knowledge in terms of the relationship between political interest and online political participation on Facebook and Twitter. 
$\mathbf{H}_{3}$ There is significant difference between Malaysian youths who do not have political knowledge and those who have political knowledge in terms of the relationship between policy satisfaction and online political participation on Facebook and Twitter.

\section{Methods}

Data was collected through a cross sectional survey of undergraduates students of Universiti Utara Malaysia during a three month period (March to May 2015). A multistage sampling method was used to select the 238 students who were surveyed. Of those who responded only 168 cases were eventually usable for final analysis. This presented an acceptable response rate of $70.5 \%$. Due to the categorical nature of the moderator political knowledge, Partial Least Squares- MultiGroup Analysis (PLS-MGA) was used to analyze data for this study [32]. This is to determine whether different parameter estimates occur for respondents without political knowledge and those with political knowledge by examining the PLS path model to see if there is significant difference in the study relationships. As a result, the subsamples to be compared were exposed to separate bootstrap analysis and the bootstrap outcomes were used for the hypothesis test of group differences.

\section{Measures}

\subsection{Access to Political Information on Facebook and Twitter}

Six items divided into three parts (Attention, Exposure and Reliance) were used to measure access to political information on Facebook and Twitter [33]. Attention to Facebook and Twitter for political information was adapted from [2] and measured on a 7-point semantic differential scale, with 1 for "No Attention" and 7 for "Lots of Attention" as anchors. Respondents were asked two questions on how much attention they pay to political information on Facebook and Twitter. For exposure to political information on Facebook and Twitter, the measurement of [34] was adapted. Respondents were asked two questions on how often they use Facebook and Twitter to access political information on Facebook and Twitter using 7 response categories ranging from "1" for "Never" to "7" for "All the time". The scale for level of reliance on social media for political information was adapted from [28]. Hence, respondents were asked two questions on how much they rely on Facebook and Twitter for political information. The 7-point scale comprised of "1" for "Never Rely" and "7" for "Heavily Rely" as anchors.

\subsection{Political Interest}

The measures for political interest were adapted from [35]. Eight items were asked on a 7-point scale with "1" for "Strongly Disagree" to "7" for "Strongly Agree". The eight items were; "None of my friends on my social network are interested in politics", "I am too busy to worry about politics", "I often discuss politics with my social network", "Politics makes no difference to people in my social network", "Politics has an impact on anything I do", "I am very interested in politics", "I know less about politics than most people in my social network", and "Sometimes politics seems so complicated I cannot understand".

\subsection{Policy Satisfaction}

Policy satisfaction was measured as a multidimensional construct with a combination of both outcome and process considerations [36]. For policy process, the measurement of [35] was adapted. As a result, six items were asked on a 7-point semantic differential scale of " 1 " for "Not at all" and "7" for "A lot" as anchors. The items bordered on if respondents were involved in any of the following; "Have a say in how policies are made in Malaysia", "Have an opportunity to be involved in the policy making process of Malaysia", "Consulted about policy making in Malaysia", "Involved in the policy making process of Malaysia", "Discuss how policies are made among their Facebook and Twitter contacts", and "Have influence on policy making when they and their friends communicate their opinion to government". All these questions were asked in the context of Facebook and Twitter. For policy outcome, the measurements of [37] and [36] were adapted. Hence, on a 7-point scale of "1" for "Very Dissatisfied" 
and "7" for "Very Satisfied", respondents were asked one question on how satisfied they are with government policies in Malaysia.

\subsection{Online Political Participation on Facebook and Twitter}

Online political participation on Facebook and Twitter was measured as a multidimensional construct with two set of questions for Facebook and two set of questions for Twitter as used by [14] for Facebook. Hence, the first two set of questions was on political activities performed and observed on Facebook, while the second two set of questions was on political activities performed and observed on Twitter. These two set of questions formed an index for online political participation on Facebook and Twitter.

\subsubsection{Online Political Participation on Facebook.}

The scale for online political participation on Facebook was adopted from [14]. Thus, 10 items were used to measure political activities performed on Facebook and 9 items were used to measure political activities observed by respondents on Facebook. One item (discussing political information about a Facebook message) was excluded from political activities observed because it is a political activity that can only be performed and not observed by friends in a network due to its private nature. Accordingly, the 10 items for political activities performed were: "Discussed political information in a Facebook message", "Posted a status update about politics", "Posted a photo about politics" "Posted a video about politics", "Posted a link about politics" "Posted a wall comment in a wall post about politics", "Posted a note about politics" "Joined or left a group about politics", "Clicked 'going' for a political event", and "Liked a political party or candidate page/became a fan of a political candidate or group". These 10 items were measured on a 7-point semantic differential scale ranging from "1" as "Never" to "7" as "Very Often". The 9 items for political activities observed on Facebook were: "Posting a status update about politics", "Posting a photo about politics" "Posting a video about politics", "Posting a link about politics" "Posting a wall comment in a wall post about politics", "Posting a note about politics" "Joining or leaving a group about politics", "Clicking 'going' for a political event", and "Liking a political party or politician's fan page/ becoming a fan of a political candidate or group". These 9 items were measured on a 7-point scale ranging from " 1 " as "Never" to "7" as "Very Often".

\subsubsection{Online Political Participation on Twitter.}

For online political participation on Twitter, 7 items were adopted from [28]. The 7 items were used for both political activities observed on Twitter and political activities performed on Twitter. For political activities performed on Twitter, the items included: "Tweet about politics", "Retweet or quote a tweet about politics", "Mention a politician or a political party", "Reply a tweet about politics", "Join a political discussion", "Join a political debate", and "Follow a politician or political party". These items were measured on a 7-point scale ranging from "1" as "Never" to "7" as "Very Often". For political activities observed on Twitter, the items included: "Tweeting a message about politics", "Retweeting or quoting a tweet about politics", "Mentioning a politician or a political party", "Replying a tweet about politics", "Joining a political discussion", "Joining a political debate" and "Following a politician or political party". These items were measured on a 7-point scale of " 1 " for "Never" to "7" for "Very Often".

\subsection{Political Knowledge}

To test for respondent's political knowledge, the scale of [30] was adapted. Consequently, respondent for this study were asked 10 political knowledge questions. These items bordered on political issues in news reports or burning issues that are or were frequently discussed within a year period in Malaysia. The 10 questions were split into information on elections, political parties (ruling parties, opposition leaders), general knowledge, administration, domestic real world events and foreign policy events. Therefore, five response categories were provided including "Don't Know". The "Don't Know" option was included because [30] noted that it minimizes the chance of randomly guessing the correct answer. Consequently, the ten political knowledge items were summed up to form an index ranging from " 0 " for incorrect answers to " 10 " for all questions answered correctly. Correct answers were coded as " 1 " and incorrect answers and "Don't Know" were coded as " 0 ". 


\subsection{Control variables.}

Two variables were used as control. Age was measured in a close-ended format and was limited to the age bracket (16-40). Therefore the options for age comprised: 16-20 years, 21-24 years, 25-29 years, 30-35 years and 36-40 years. Gender was dummy coded as "0" for male and " 1 " for female.

\section{Results and Discussion}

The results of the PLS-MGA as shown in Table 1 indicates the group differences for respondents without political knowledge and those with political knowledge in terms of their moderating effect on the relationship between the exogenous variables and the endogenous variable.

Table 1. PLS-MGA for Respondents Without or With Political Knowledge

\begin{tabular}{|l|c|c|c|}
\hline Relationship & $\begin{array}{c}\text { Path Coefficients-(W/O PK Group 1-W PK } \\
\text { Group 2) }\end{array}$ & $\begin{array}{c}\text { p-Value } \\
\text { (W/O PK Group 1-W PK } \\
\text { Group 2) }\end{array}$ & Findings \\
\hline APIFT -> OPPFT & .373 & .991 & Supported \\
\hline PI -> OPPFT & .344 & .011 & Supported \\
\hline PS -> OPPFT & .039 & .628 & $\begin{array}{c}\text { Not } \\
\text { Supported }\end{array}$ \\
\hline
\end{tabular}

*W/O PK- Without Political Knowledge

W PK - With Political Knowledge

Hypothesis 1 stated that there is significant difference between Malaysian youths who do not have political knowledge and those who have political knowledge in terms of the relationship between access to political information on Facebook and Twitter and online political participation on Facebook and Twitter. This hypothesis was supported as shown by the significant result $(\beta=.991 . \mathrm{p}>.95)$ (See Table 1). Hypothesis 2 stated that there is significant difference between Malaysian youths who do not have political knowledge and those who have political knowledge in terms of the relationship between political interest and online political participation on Facebook and Twitter. This hypothesis was supported as evidenced by the significant result $(\beta=.344, \mathrm{p}<.10)$ (See Table 1$)$. Hypothesis 3 stated that there is significant difference between Malaysian youths who do not have political knowledge and those who have political knowledge in terms of the relationship between policy satisfaction and online political participation on Facebook and Twitter. This hypothesis was not supported because the path coefficient between the two subsamples are not significant due the following parameters $(\beta=.039, p>.05)$.

Therefore in line with the findings of [26], the results of this study indicates that political knowledge moderated the relationship between access to political information on Facebook and Twitter and online political participation on Facebook and Twitter. Similarly, the result of this study which indicates that political knowledge moderated the relationship between political interest and online political participation on Facebook and Twitter is in congruence with the findings of [12]. Additionally, the fact that political knowledge did not moderate the relationship between policy satisfaction and online political participation on Facebook and Twitter is supported by the statement of [22].

\section{Conclusion}

This study examined the role of social media in youth's online political participation by assessing the potential of political knowledge to enhance this form of participation among Malaysian youths from a cognitive engagement perspective. Thus, this study contributes to the modelling of cognitive engagement theory by introducing political knowledge as a moderator and examining the theory from social media perspective. Furthermore, the study lends empirical support to the relationship between variables of the theory and online political participation thus adding to the body of knowledge on political participation. Also, this study has proved that political knowledge play an important role in engendering political participation among Malaysian youths. 
Nevertheless, this study is limited in the nature of its design as the cross sectional survey approach which was used did not allow for causal inferences to be made from the population over a long period of time. Thus, it is recommended that a longitudinal design which could measure online political participation among youths over a long period of time needs to be carried out. Also, online political participation of youths on Facebook and Twitter were assessed using self- report measures. Thus, other measures which could provide a more objective perspective on their activities is recommended. Furthermore, generalizing results from this study may be limited in that participants were from a public university which may not provide adequate representation of youths in Malaysia. Thus, future studies could be expanded to cover youths in other forms of tertiary institutions or those not in school to enhance the generalizability of results of the study. Lastly, since political knowledge did not moderate the relationships on all levels, perhaps it could be introduced as a mediator. Investigating such mediating effect in future research could provide significant results in all cases.

\section{Acknowledgement}

This research is funded by Univesiti Utara Malaysia under the postgraduate incentive research grant scheme $(\mathrm{S} / \mathrm{O}$ Code: 15697).

\section{References}

1. S. Boulianne. Info. Comm, \& Society., 18, 5, 524-538 (2015)

2. M. Yamamoto \& M. Kushin. Journal of Computer-Mediated Comm. 19, 3, 430-445 (2013)

3. J. Groshek. International Comm. Gazette, 74, 8, 750-768 (2012)

4. S. Vissers \& D. Stolle, (2014). Journal of Info. and Tech. Politics, 11, 3, 259-275 (2015)

5. K. Varnali, V. Gorgulu. Info. Comm. and Society. 18, 1, 1-16 (2014)

6. L. Ke, H. Starkey, London Review of Educ. 12, 1, 50-62. http://www.ingentaconnect.com/content/ioep. (2014)

7. M.J. Kushin, M. Yamamoto, Mass Comm. and Society, 13, 5, 608-630 (2010)

8. S. Stieglitz, L. Dang-Xuan. Social Network Analysis and Mining, 3, 4, 1277-1291 (2013)

9. M.V. Mongkuo, M.L. Lyon, M.B. Hogan, G. Delore, Journal of Political Science and Public Affairs, $2,3$. (2014)

10. M. Wojcieszak, International Journal of Comm. 6, 11, 255-256. (2012)

11. H. Gil de Zúñiga, N. Jung, S. Valenzuela, Journal of Computer-Mediated Comm., 17, 3, 319-336 (2012)

12. M.C.W. Charles. Impact of digital inequality on civic and political participation. Dissertation, ProQuest (2010)

13. N. Okoro, K.A. Nwafor. Global Journal of Arts and Hum and Social Sci. 1, 3, 29-46. (2013)

14. J. Vitak, P. Zube, A. Smock, C.T. Carr, N. Ellison. C. Lampe. Cyber Psyc., Beh. and Social Networking, 14, 3, 107-114. (2011)

15. R. Inglehart. The silent revolution: Changing values and political styles among western publics. Princeton, New Jersey: Princeton University (1977)

16. D. Odunlami. New Media and Mass Communication. Retrieved October 28, 2014 from www.iiste.org. (2014)

17. A. Salman, S. Saad. Mediterranean Journal of Social Sci, 6, 4, 88. (2015)

18. C.E. Uzochukwu. U.E. Patricia. C.A. Ukueze. International Journal of Social Relevance Comm. 2 , 11 (2014)

19. A.T. Titus-Fannie. C.S. Akpan. M.O. Tarnongo. IOSR Journal of Hum and Social Sci. 6(5), 32-44. www.iosrjournals.orgs. (2013)

20. R. J. Dalton. The Journal of Politics. 46, 264 -284 (1984)

21. Y. Theocharis, E. Quintelier. New Media and Society. 1-20. (2014)

22. C. Pattie, P. Seyd. P. Whiteley. Citizenship in Britain: Values, participation and democracy. Cambridge: Cambridge Uni Press. (2004)

23. I. Rahmawati. ProQuest Dissertation (2014)

24. M.R.Vincente. A. Novo. Govt. Info. Quarterly, 31, 3, 379-387. (2014)

25. K. Kaufhold, S. Valenzuela., H. Gil de Zuniga. Journalism \& Mass Comm. Quarterly, 87, 3-4, 515-529. (2010)

26. S. Valenzuela. American Behavioral Scientist, 57, 7, 920-942. (2013)

27. B. O'Neill. Canadian Policy Research Networks. (2006) 
28. T.J. Johnson. B.K. Kaye. Journal of Computer Mediated Comm. 19, 4, 957-974. (2014)

29. J.K. Raoof. H.B. Zaman, A. Ahmad. A. Al-Qaraghuli. International Journal of Phy. Sci., 8, 12, 1143-1148. (2013)

30. D.V. Dimitrova. A. Shehata, J. Stromback. L.W. Nord. Comm.Research. 41, 1, 95-118. (2014)

31. C.J. Tolbert. R.S.McNeal. Political research quarterly, 56, 2, 175-185. (2003)

32. J. Henseler. Challenges at the interface of data analysis, computer science, and optimization, 495-501. (2012)

33. W.P. Eveland. D.A. Scheufele. Pol. Comm. 17, 215-237. http://www.tanfonline.com/loi/upcp20. (2000)

34. M.A.Bekafigo. A. McBride. Social Science Computer Review, 31, 5, 625-643. (2013)

35. P.F. Whiteley. The political science perspective research report. RR 631 (2005)

36. P.F. Whiteley. H.D. Clarke. D. Sanders. M. Steward. Presented at the Conference on Citizens and Politics in Britain Today: Still a Civic Culture? London School of Economics (2013)

37. J. Shore. Paper Prepared for the PartiRep Workshop "Conceptualizing Political Participation" Mannheim(2014)

38. A. Tumasjan,T.O Sprenger, P.G. Sandner, I.M. Welpe. Proceeding of the fourth International AAA1 conference on Weblogs and Social Media Predicting, 174-184, (2010) 